\title{
Empirical therapy for nonhospitalized patients with community-acquired pneumonia
}

\author{
H. Laurichesse*, F. Robin*, L. Gerbaud**, P. Pochet+, F. Gourdon*, J. Beytout*, M. Rey*, \\ and the Study Group of General Practitioners
}

Empirical therapy for nonhospitalized patients with community-acquired pneumonia. $H$. Laurichesse, F. Robin, L. Gerbaud, P. Pochet, F. Gourdon, J. Beytout, M. Rey, and the Study Group of General Practitioners. OERS Journals Ltd 1998.

ABSTRACT: A prospective survey involving a group of 95 general practitioners (GPs) in France was conducted to describe antibiotic therapy prescribed for outpatients with community-acquired pneumonia (CAP).

A total of 173 cases of $\mathrm{CAP}$, defined by the association of fever and pulmonary focal crackles and/or radiological changes consistent with a pulmonary infection, were reported between February 1993 and March 1994: 84 males and 89 females (mean age: 48 yrs) of whom $45 \%$ had no underlying disease. Nineteen (11\%) were immediately hospitalized and the remaining 154 out-patients were treated without microbiological investigation.

First-line antibiotic therapy was amoxicillin or amoxicillin-clavulanic acid combination $(57 \%)$, a first or second generation cephalosporin $(12 \%)$, ceftriaxone $(8 \%)$ oral broad-spectrum cephalosporin (3\%), a macrolide (16\%), a tetracycline $(1 \%)$ and a fluoroquinolone $(2 \%)$. A total of $120(78 \%)$ patients recovered with no change in treatment and $34(22 \%)$ patients failed to improve: 18 were hospitalized and 16 had a second-line therapy, mainly a macrolide or a quinolone. Five patients died at hospital. The overall mortality was $3 \%$, and $14 \%$ in hospitalized patients.

Empirical therapy using a betalactam to target a presumed pneumococcal infection, in agreement with European guidelines, is appropriate for out-patients with mild lobar community-acquired pneumonia.

Eur Respir J 1998; 11: 73-78.
*Infectious disease ward, and **Epidemiology, Prevention and Public Health Laboratory, Hôtel-Dieu, University Hospital of Clermont-Ferrand, Clermont-Ferrand, France ${ }^{+}$Commission Epidémiologie du Conseil Régional de Formation Médicale Continue d'Auvergne, Clermont-Ferrand, France.

Correspondence: H. Laurichesse, Service des Maladies Infectieuses et Tropicales, Hôtel-Dieu, CHU de Clermont-Ferrand, 63000 Clermont-Ferrand, France. Fax: 003347331 6265.

Keywords: Community-acquired pneumonia, general practice, general practitioners, hospitalization, out-patients, therapy

Received: February 21997

Accepted after revision August 311997

This study was financially supported by l'Institut pour la Formation et le Développement de la Médecine Générale (IFED-MG), la Commission Epidémiologie du Conseil Régional de Formation Médicale Continue d'Auvergne and the Centre d'Etudes des Maladies Infectieuses et des Maladies du sang (CEMIMS)
Community-acquired pneumonia (CAP) remains, at the end of the 1990s, a frequent and life-threatening infection in young children, elderly individuals and immunosuppressed patients [1-4]. Streptococcus pneumoniae is the leading identified cause of CAP in hospitalized patients $[5,6]$ and in patients investigated in the community [6-9]. However, extensive microbial investigations lead to the identification of a pathogen in less than one half of the immunocompetent patients admitted to hospital [5] or treated in the community [7-9] and there are usually no specific clinical or radiological features which suggest with confidence the aetiological agent involved in CAP $[2,3$, 10]. In addition, an increasing proportion of S. pneumoniae with decreased susceptibility to penicillin has been reported in European countries [11]. Despite an increasing availability of new oral broad-spectrum drugs, antibiotic therapy for CAP remains a critical issue $[2,4,10]$.

General practitioners (GPs) have to consider the need for hospital admission and for biological and radiological investigations in patients with CAP, and they have to initiate antibiotic therapy for out-patients and evaluate the outcome under therapy. In contrast to numerous and extensive studies on the management and outcome of hospitalized patients with CAP [2-5, 12-14], few studies have addressed the management of nonhospitalized patients with CAP [10].
We therefore set up a group of GPs in the Auvergne, France, to assess routine management of patients with CAP treated outside hospital. We report the results of a 14 month survey focused on the antibiotic therapy for nonhospitalized patients with CAP.

\section{Methods}

\section{Formation of a group of GPS}

The study was conducted with GPs in the Puy-de-Dôme, Auvergne, a central and predominantly rural province in France. In January 1993, the infectious diseases ward of the Regional University Hospital in Clermont-Ferrand, sent a letter to all the GPs registered at the Puy-de-Dôme Local Medical Council, inviting them to participate in a prospective survey of the routine management of ambulatory patients with CAP.

Ninety-five (15\%) GPs agreed to participate in this study and, during the 14 month study period, to report every case of CAP fulfilling the case definition. They were all volunteers and did not receive any financial remuneration. 


\section{Case definition}

A CAP was defined as the acute onset of fever (central temperature $>38.5^{\circ} \mathrm{C}$ ) with focal crackles on chest examination and/or radiological changes consistent with a pulmonary infection, in patients $>3$ yrs of age, living in the community (including residential institutions), and who had not been hospitalized during the week before the diagnosis of acute pneumonia. Patients with suspected aspiration pneumonia were excluded from the study.

\section{Study monitoring}

A two-part questionnaire was designed for the GPs to complete at different stages in the management of patients with CAP. In the first part, the demographic characteristics and medical history of patients (underlying disease, specific risk factors, recent vaccination against influenza and pneumococcal infections) were reported along with the clinical features of the episode of pneumonia and the initial decisions taken by the GP: hospitalization of the patient, biological, radiological, and/or microbial investigations performed (including blood culture, sputum examination and serological testing), and treatment offered: monotherapy or combination therapy, doses, route of administration, prescribed duration of treatment.

The second part focused on the follow-up of the patient and the outcome of pneumonia under treatment. The results of investigations and clinical outcome, including the duration of treatment and the number of days off work and the use of additional or alternative treatment, were recorded. The completed forms were sent to the principal investigator for the patient to be included in the study.

Every month, a letter was sent to all the GPs informing them of the progress of the study and the GPs also made a monthly return of number of cases diagnosed and included in the study. During the study period, from February 1, 1993 to March 30, 1994, GPs were contacted on a regular basis to collect any missing data and confirm that all cases of CAP had been reported. Regular meetings were organized to improve the monitoring of the study and the communication between all investigators.

\section{Statistical analysis}

The data were rendered anonymous, and then checked, stored and analysed in Epi Info (USA Inc., GA, USA) [15]. Out-patient groups were defined by whether their initial therapy was narrow spectrum antibiotics such as amoxicillin, first generation cephalosporins or macrolides, or broad-spectrum agents such as amoxicillin-clavulanic acid combination, second or third generation cephalosporins, or fluoroquinolones. Age groups of patients were defined as follows: $<16$ yrs, $16-65$ yrs and $>65$ yrs. The Chi-squared test was used to compare proportions and the Student t-test to compare quantitative variables.

\section{Results}

From February 1, 1993 to March 31, 1994, 201 cases of CAP were reported. Twenty eight cases were excluded from the analysis: six patients were $<3$ yrs of age, five cases did not fulfil the case definition of CAP, and information on initial management or follow-up of 17 patients was missing.

A total of $173(86 \%)$ CAPs meeting the criteria were included in the study: all patients had fever and crackles disclosed by their GP and/or radiographic evidence of pneumonia. One hundred and fifty five patients (90\%) patients had radiologically confirmed pneumonia.

\section{Frequency and seasonality of CAP}

The mean number of CAPs reported by participating GPs during the study period was 1.8 cases per GP and the average number was 1.72 cases of CAP per GP during the first 12 months of the study. Twenty two (23\%) GPs did not report any cases and $49(52 \%)$ GPs reported one or two cases during the study. There was a seasonal distribution in the number of CAPs: $62(36 \%)$ CAPs were reported from December to February and 30 (17\%) CAPs from June to August.

\section{Patients}

There were 84 male and 89 female patients (male:female sex ratio $=0.94$ ) whose mean \pm SD age was $48 \pm 25$ yrs (range: 3-93). Mean age did not significantly differ between male and female. Twenty eight (16\%) CAPs were reported in patients $<15 \mathrm{yrs}, 56(32 \%)$ in patients $>65 \mathrm{yrs}$. Sixty eight $(39 \%)$ patients were in employment, $65(37 \%)$ retired, $30(17 \%)$ school-children or students and $10(6 \%)$ unemployed. One hundred and sixty three $(94 \%)$ patients were living at home, alone $(13 \%)$ or with other members of the family $(81 \%)$; seven $(4 \%)$ were living in residential institutions and $3(2 \%)$ with relatives.

The underlying diseases of the patients are presented in table 1 . No patients were reported to have a human immunodeficiency virus (HIV) infection or a drug-related cause of immunosuppression. Forty six $(27 \%)$ patients had been immunized against influenza (mean age: $70 \mathrm{yrs}$ ) and three $(2 \%)$ patients $>65$ yrs with a history of cardiopulmonary disease had been immunized against pneumococcal infection.

\section{Initial management}

At presentation, all patients had acute fever (mean temperature $=39.1^{\circ} \mathrm{C}$, range: $\left.38.5-41.1^{\circ} \mathrm{C}\right)$ and $74(43 \%)$ patients had constitutional symptoms (sweating, shivering and myalgia). Initial pulmonary symptoms included nonproductive cough (48\%), productive cough (40\%), thoracic pain $(44 \%)$, and increased breathlessness $(43 \%)$.

Initial chest examination detected pulmonary crackles in $131(76 \%)$ patients, other abnormal chest signs in seven $(4 \%)$ and was reported as clear in $35(20 \%)$ patients. Extrapulmonary symptoms included gastro-intestinal symptoms in $12(7 \%)$ patients and upper respiratory symptoms in $11(6 \%)$. At presentation, one patient was shocked with systolic hypotension, $26(15 \%)$ were breathless at rest and four $(2 \%)$ had altered levels of consciousness. 
Table 1. - Underlying diseases in 173 patients with community-acquired pneumonia reported by a group of 95 general practitioners, France, February 1993 to March 1994

\begin{tabular}{lcc}
\hline & \multicolumn{2}{c}{ Patients* } \\
\cline { 2 - 3 } Underlying diseases & $\mathrm{n}$ & $\%$ \\
\hline No previous medical history & 78 & 45 \\
Pulmonary diseases & 40 & 23 \\
Chronic pulmonary obstructive disease & 19 & 11 \\
History of acute pneumonia & 11 & 6 \\
History of pulmonary tuberculosis & 7 & 4 \\
History of pulmonary embolism & 2 & 1 \\
Bronchial cancer & 1 & 0.6 \\
Cardiovascular diseases & 50 & 29 \\
Ischaemic heart disease/cardiac failure & 20 & 12 \\
Hypertension & 16 & 9 \\
Rhythm abnormalities and vavulopathy & 8 & 5 \\
Arterial or venous insufficiency & 6 & 3 \\
Other medical history & 43 & 25 \\
Diabetes mellitus and thyroid disorders & 13 & 8 \\
Breast cancer & 8 & 5 \\
Neuropsychiatric disorders & 8 & 5 \\
Hodgkin disease/anaemia & 5 & 3 \\
Liver cirrhosis & 4 & 2 \\
Others & 5 & 3 \\
\hline
\end{tabular}

*: Some patients have multiple diseases.

Nineteen (11\%) patients were hospitalized following initial clinical examination. They were more likely to live alone $(\mathrm{p}=0.005)$, to be retired $(\mathrm{p}=0.054)$, to have a previous cardiac history $(\mathrm{p}=0.059)$, to have pulmonary crackles $(p=0.014)$ and to have a dyspnoea with effort $(p=0.019)$ or a dyspnoea at rest $(\mathrm{p}=0.0003)$.

No blood culture or sputum examination was performed in the remaining 154 out-patients.

A total of $100(65 \%)$ out-patients had a chest radiograph before antibiotic therapy: these patients were more likely to be younger ( $\mathrm{p}=0.002)$, to live in Clermont-Ferrand $(p=0.0034)$ and to have pulmonary crackles $(p=$ 0.033). Chest radiographs disclosed unilobar alveolar consolidation in 83 patients, unilateral multilobar alveolar consolidation in two, bilateral alveolar consolidation involving three lobes in two, and bilateral interstitial pattern in eight. A pleural effusion was suspected in five patients, and four patients had an initial normal chest radiograph.

In $48(31 \%)$ out-patients laboratory tests were performed providing a leucocyte count $>15,000$ cells $\mathrm{mm}^{-3}$ in 40 patients. In addition, erythrocyte sedimentation rate (ESR) or C-reactive protein (CRP) were found elevated in all 34 patients tested.

\section{First-line antibiotic therapy}

First-line antibiotic therapy was a monotherapy in 143 (93\%) patients and a beta-lactam for $115(75 \%)$ patients (table 2). Antibiotic therapy was mainly prescribed via the oral route. Of 33 patients treated with amoxicillin alone, oral amoxicillin was prescribed in $20(60 \%)$ and the intramuscular form in $13(40 \%)$. Of 55 patients treated with amoxicillin-clavulanic acid combination, the oral form was prescribed in $51(93 \%)$ patients and the intravenous form in four $(7 \%)$.
Table 2. - First-line antibiotic therapy for 154 out-patients with community-acquired pneumonia, France, February 1993 to March 1994

\begin{tabular}{lrr}
\hline & \multicolumn{2}{c}{ Out-patients } \\
\cline { 2 - 3 } Initial therapy & $\mathrm{n}$ & $\%$ \\
\hline Monotherapy & 143 & 93 \\
Amoxicillin & 33 & 23 \\
Amoxicillin-clavulanic acid combination & 49 & 34 \\
First/second generation cephalosporin & 17 & 12 \\
Oral broad-spectrum cephalosporin & 4 & 3 \\
Ceftriaxone & 12 & 8 \\
Macrolide & 23 & 16 \\
Fluoroquinolone & 3 & 2 \\
Tetracycline & 1 & 1 \\
Chloramphenicol & 1 & 1 \\
Combination therapy & 11 & 7 \\
Amoxicillin-clavulanic acid + macrolide & 4 & 3 \\
Amoxicillin-clavulanic acid + quinolone & 2 & 1 \\
Amoxicillin + aminoglycoside & 1 & 1 \\
Second generation cephalosporin + & 3 & 2 \\
macrolide & & \\
Second generation cephalosporin + & 1 & 1 \\
chloramphenicol & & \\
Total & 154 & 100 \\
\hline
\end{tabular}

A narrow spectrum antibiotic was prescribed for 67 (44\%) patients and a broader spectrum agent for $87(56 \%)$ patients. The age of the patients, a previous history of cardiopulmonary diseases and radiological features were not identified as predictors for the antibiotic selection. However, antibiotic selection was significantly associated $(p=0.007)$ with the results of the initial chest examination. Out-patients with crackles at presentation were more likely to be treated with a broad-spectrum antibiotic $(65 \%$ : 73 out of 113) than patients with no crackles (35\%: 40 out of 113 ; odds ratio $(\mathrm{OR})=1.89,95 \%$ confidence interval (CI): 1.2-2.9). Out-patients with crackles were treat-ed with amoxicillin-clavulanic acid combination $(n=41)$, a second or third generation cephalosporin $(n=20)$, a quinolone $(n=3)$ or a combination therapy $(n=9)$ and 40 other patients with crackles were treated with amoxicillin $(\mathrm{n}=$ $21)$, a macrolide $(\mathrm{n}=14)$ or a first generation cephalosporin $(\mathrm{n}=5)$. In addition, patients with a lobar alveolar consolidation on initial radiographs were more likely to be treated with broad-spectrum agents than patients with other radiological features $(\mathrm{p}=0.09, \mathrm{OR}=1.27,95 \%$ CI: 0.9 1.7).

\section{Evaluation and outcome of the patients}

A clinical evaluation was performed by GPs at different times during the follow-up of the patients. All out-patients were re-examined during the 2-4 day period following the initiation of treatment.

First-line antibiotic therapy was unchanged in 120 $(78 \%)$ patients. On average, no patient had fever beyond $3.5 \pm 2.1$ days. In addition, constitutional and pulmonary symptoms progressively improved in 98 patients. However, 21 of these $120(18 \%)$ patients had new clinical features including sputum in 10 , pulmonary crackles in seven, and thoracic pain in three when they were first re-examined. Forty seven of these $120(39 \%)$ patients had 
a chest radiograph during follow-up. A second radiograph was performed for 42 patients and the comparison showed an improvement in 36 patients. In 26 patients, intramuscular or intravenous antibiotic therapy was switched to an oral route.

\section{Second-line antibiotic therapy}

Thirty four (22\%) out-patients were hospitalized or had a second-line therapy. They all had persistent fever, cough, constitutional symptoms or thoracic pain and new clinical features occurred in 27 patients: cough in six, focal pulmonary crackles in 15 , shock in six, and constitutional symptoms in eight.

Eighteen (nine males, nine females, mean age $60 \mathrm{yrs}$ ) were hospitalized: they were more likely to be older $(\mathrm{p}=$ $0.016)$ and to have a history of cardiac failure $(p=0.007)$ than others. These patients had been treated with the amoxicillin-clavulanic acid combination $(n=11)$, a macrolide $(n=3)$, or ceftriaxone $(n=4)$. They were treated at hospital with an intravenous combination of a beta-lactam and a macrolide or a fluoroquinolone.

A chest radiograph was performed in $12(70 \%)$ outpatients who failed to improve, showing alveolar consolidation in 10 (associated with a pleural effusion in two patients), and an interstitial pattern in two. Four patients tested had an increased leucocyte count.

Sixteen out-patients received a second-line therapy presented in table 3 .

\section{Final evaluation}

Mean \pm SD duration of antibiotic therapy for the 136 outpatients was $13.7 \pm 5.8$ days (range: 5-40 days), longer $(\mathrm{p}=0.0003)$ in patients who received a second-line therapy (16.7 days) than others (9.6 days). Mean \pm sD duration of treatment beyond apyrexia, was $9.6 \pm 5.4$ days. Mean \pm SD duration off work, available for 58 (85\%) employed patients was $14.8 \pm 10.3$ days (range: $0-50$ days). Five patients (three males, two females, mean age 76 yrs) with a previous history of cardiac and/or pulmonary disease died at hospital. The overall mortality rate for CAP was $3 \%$ (95\% CI: $0.4-5.3 \%$ ) in the population study and $14 \%$ (95\% CI: 2.4-24.5) in hospitalized patients.

Table 3. - Switch to second-line therapy in 16 out-patients with community-acquired pneumonia, France, February 1993 to March 1994

\begin{tabular}{llc}
\hline First-line therapy & Second-line therapy & $\begin{array}{c}\text { Patients } \\
\mathrm{n}\end{array}$ \\
\hline Amox & Macrolide & 4 \\
& Amox-Clav & 1 \\
& Third generation ceph & 1 \\
& Tetracycline & 1 \\
& Macrolide & 3 \\
Amox-Clav & Amox + macrolide & 1 \\
& Quinolone & 1 \\
First generation ceph & Amox-Clav & 1 \\
Third generation ceph & Amox-Quinolone & 1 \\
Amox-Clav + Macrolide & Amox-Clav + Ceph & 1 \\
Amox + Aminoglycoside & Quinolone + Pris & 1 \\
\hline Amox: amoxicillin; Clav: clavulanic acid; Ceph: cephalosporin; \\
Pris: pristinamycine. & &
\end{tabular}

\section{Discussion}

Initial treatment for CAP was predominantly a beta-lactam (amoxicillin 23\%, amoxicillin-clavulanic acid combination $34 \%$ ) and a few patients were treated with a macrolide. Patients with focal crackles were more likely to be treated with a broad-spectrum antibiotic. This empirical strategy is consistent with French [16, 17], other European [18-19], and North American guidelines [20, 21], which all recommend targeting pneumococcal infection.

Over three quarters of out-patients recovered with no change in initial therapy, but the average duration of therapy (13.7 days and 9.6 days beyond apyrexia) is longer than that recommended (5-10 days for a mild pneumococcal pneumonia). A shorter duration may improve compliance, reduce the cost and the likelihood of side-effects related to the drugs. The optimal timing for sequential therapy (switch from parenteral to oral therapy) has to be defined, but implies that adequate tissue and serum levels are achieved through an oral route [16, 20]. Taking account of the increasing prevalence of pneumococcal strains with decreased penicillin sensitivity [22, 23], 3 $\mathrm{g} \cdot$ day $^{-1}$ of oral amoxicillin for patients with CAP has been recently recommended in France [24]. However, assessment of the local prevalence of pneumococcal resistance in CAP would be of relevance for appropriate clinical decision-making in the future.

Twenty two per cent of out-patients failed to improve within the days following therapy, leading to the hospitalization of those who were old or had a history of cardiorespiratory diseases and to the prescription of a second-line therapy (mainly a macrolide or a quinolone) for the remaining patients. Although extrapulmonary pneumococcal infections (i.e. sinusitis, pulmonary abscess or empyema) may cause persistent fever, inappropriate treatment may be due to either a resistant aetiological agent (e.g. S. pneumoniae with decreased sensibility to penicillin or Haemophilus sp. secreting a betalactamase), or an agent unresponsive to the drug used (e.g. intracellular bacteria, viruses). In addition, Mycobacterium tuberculosis or Pneumocystis carinii may cause CAP and noninfectious diseases may mimic pneumonia [25].

Radiographs may help GPs in detecting sinusitis, empyema, pulmonary abscess, tuberculosis or $P$. carinii pneumonia. However, the aetiological agent responsible for an "apparent failure" of the therapy is difficult to identify, even with extensive investigations which would require hospitalization. Therefore, guidelines suggest a switch to or the addition of a macrolide when patients do not improve on a beta-lactam. This recommendation has been implemented for out-patients who could be safely treated at home.

The overall hospitalization rate $(21 \%)$ is consistent with previous studies [7, 11], except one conducted in Finland where the hospitalization rate was $42 \%$ [26], and our study outlines the impact of the familial and medical environment of the patients in the hospitalization decision, as reported in the recent studies [27-30]. The overall mortality rate $(3 \%)$, consistent with the characteristics of the population study and the high proportion of mild pneumonia, is in agreement with previous reports [31, 32].

Studies designed to assess routine management of patients with CAP may benefit from a specific case definition 
to exclude acute bronchitis and acute exacerbation of chronic bronchitis. However, there is no definite case definition: chest examination may be inconclusive and evidence of pneumonia would therefore require radiological confirmation which may be difficult to perform in outpatients. Focal pulmonary crackles were used as a clinical criterion since they achieved a high likelihood ratio against the radiographic reference standard [33]. An additional criterion, such as antibiotic prescription, would not have improved the case definition since antibiotics are often prescribed for patients with bronchitis in France.

The low reported number of CAP per GP (1-2 cases $\left.\cdot \mathrm{yr}^{-1}\right)$ suggests that cases of CAP may have been missed [7, 8, 26]. Patients with chronic cardiopulmonary diseases, cancer, organ transplant or HIV infection, at increased risk of developing pneumonia, are more likely to be managed in France by specialists as out-patients or to be hospitalized. Cases of CAP may have been unreported in the elderly since fever may be absent [34], and chest examination may be inconclusive. Without radiographic confirmation these cases were not included in the study.

This study, designed to provide information on the routine management of out-patients with community-acquired pneumonia, shows that general practitioners implement national recommendations for therapy and that $80 \%$ of patients are treated as out-patients, suggesting the key role of general practitioners in France in managing immunocompetent out-patients with mild pneumonia. Therefore, the evaluation of their therapeutic practice is warranted. Future guidelines for the management of out-patients with community-acquired pneumonia should take account of the limited resources of general practitioners for their clinical and therapeutic decisions.

\begin{abstract}
Acknowledgements: The authors wish to thank the study group of general practitioners for their active participation in this survey: J.F. Allewaert, J. Auzary, M. Barjaud, D. Barres, L. Barthelemy, R.L. Bellon, E. Begon, M. BerteroCondat, V. Bertrand-Jarrousse, I. Biat, J.P. Blettery, T. Bogli, J.C. Bonvin, P. Bruel, T. Buferne, J.M. Calut, O. Caux, P. Caux, A. Chabanon, C. Chalafre, P. Chambon, F. Christofeul, B. Clement, J. Collard, J. Dardillat, J.L. Delhomme, J. Desvignes, F. Dhenain, J.B. Dubois, N. Dubourgnoux, C. Dubreuil, A.F. Dykczyz, C. FalatinMangot, C. Falatin, P. Fargeix, J.P. Fauchon, J.C. Ferrandon, F. Flores, A. Foa, B. Follanfant, C. Gardon-Mollard, I. Gazagne, M.J. Gilbert, C. Gimbergues, P. Grassy, J.P. Griffoux, S. Guignard, J. Guillere, A.M. Harrand, G. Jury, F. Lapalus, M. Lavignon-Veisleib, A. Ledu, O. Lelièvre, H. Leloup, J.P. Lerch, C. Levy, R. Liberce, P. Manry, A. Marlois, P. Maublant, J.P. Mazen, P. Mery, N. Moncenis, J.C. Montorcier, O. Mougel, J.P. Mouilhaud, P. Nugeyre, D. Olleon, L. Pages, P. Peigneux, F. Pepin, Y. Pertuet, H. Pinet, J.J. Planche, P. Pochet, J.C. Pujo, H. Raffestin, P. Ravel, P. Ribeyrolles, M.C. Riol, D. Rivoire, C. RousselFeybesse, J.M. Roye, D. Schwartz-Lafont, J.F. Serre, C. Tartière-Lafont, C. Taque, M. Tessonnière, P.M. Therond, B Thevenot, D. Trauchessec, C. Verdier, Y. Vincent, T. Zeganadin.
\end{abstract}

\section{References}

1. Garibaldi RA. Epidemiology of community-acquired respiratory tract infections in adults: incidence, aetiology, and impact. Am J Med 1985; 78: 32-37.
2. Donowitz GR, Mandell GL. Acute pneumonia. In: Mandell GL, Douglas RG, Benett JE, eds. Principles and Practice of Infectious Diseases. 4th Edn. New York, Churchill Livingstone, 1990; pp. 619-637.

3. Marrie TJ. Community-acquired pneumonia. Clin Infect Dis 1994; 18: 501-515.

4. Bartlett JG, Mundy LM. Community-acquired pneumonia. New Engl J Med 1995; 333: 1618-1624.

5. Fang GD, Fine M, Orloff J, et al. New and emerging aetiologies for community-acquired pneumonia with implications for therapy. A prospective multicenter study of 359 cases. Medicine 1990; 69: 307-316.

6. Mayaud C, Parrot A, Houacine S, Denis M, Akoun G. Epidémiologie des germes responsables des infections communautaires des voies respiratoires inférieures. Méd Mal Infect 1992; 2 (Suppl.): 130-139.

7. Woodhead MA, Macfarlane JT, McCracken JS, Rose DH, Finch RG. Prospective study of the aetiology and outcome of pneumonia in the community. Lancet 1987; i: 671-674.

8. Macfarlane JT, Colville A, Guion A, Macfarlane RM, Rose DH. Prospective study of aetiology and outcome of adult lower-respiratory-tract infections in the community. Lancet 1993; 341: 511-514.

9. Francioli P, Moser F. Epidémiologie des pneumonies diagnostiquées en pratique ambulatoire. Rev Méd Suisse Romande 1992; 112: 337-339.

10. Pomilla PV, Brown RB. Outpatient treatment of community-acquired pneumonia in adults. Arch Intern Med 1994; 154: 1793-1802.

11. Klugman KP. Pneumococcal resistance to antibiotics. Clin Microbiol Rev 1990; 3: 171-176.

12. British Thoracic Society Research Committee. Community acquired pneumonia in adults in British hospitals in 1982-1983: a survey of aetiology, mortality, prognostic factors and outcome. $Q J$ Med 1987; 62: 195-200.

13. MacFarlane J, Ward MJ, Finch RG, Macrae AE. Hospital study of adult community requiring pneumonia. Lancet 1982; ii: 255-258.

14. Marrie T, Durant H, Yates L. Community-acquired pneumonia requiring hospitalisation: 5-year prospective study. Rev Infect Dis 1989; 11: 586-599.

15. Dean AG, Dean JA, Burton AH, Dixker RC. Epi Info, Version 5: a word processing, database, and statistics programme for epidemiology on microcomputers. USA, Georgia, Centers for Disease Control-WHO, 1990.

16. Société de Pathologie Infectieuse de Langue Française. Les infections des voies respiratoires. Méd Mal Infect 1991; 21 (Suppl.): 1-8.

17. Convention Nationale destinée à organiser les rapports entre les médecins libéraux et les caisses d'Assurance Maladie. 1994. Avenant $n^{\circ} 1$, thème $n^{\circ} 2: 7$.

18. British Thoracic Society. Guidelines for the management of community-acquired pneumonia in adults admitted to hospital. Br J Hosp Med 1993; 49: 346-350.

19. Grupo de trabajo de la SEPAR. Normativa sobre diagnostic y tratamiento de las neumonias. Barcelona, Editiones Doyma, 1992.

20. Niederman MS, Bass JB, Campbell GD, et al. Guidelines for the initial management of adults with community-acquired pneumonia: diagnosis, assessment of severity, and initial antimicrobial therapy. Am Rev Respir Dis 1993; 148: 1418-1426.

21. Mandell LA, Niederman MS. The Canadian communityacquired pneumonia consensus group: antimicrobial treatment of community acquired pneumonia in adults: a conference report. Can J Infect Dis 1993; 4: 25-28. 
22. Geslin P, Buu-Hoi A, Frémaux A, Acar JF. Antimicrobial resistance in Streptococcus pneumoniae: an epidemiological survey in France, 1970-1990. Clin Infect Dis 1992; 15: 75-98.

23. Weber M, Roussel-Delvallez M, Laurans G, et al. Enquêtes épidémiologiques régionales sur la résistance aux antibiotiques de $S$. pneumoniae: résultats préliminaires de 6 observatoires régionaux. Méd Mal Infect 1997; 27 (Suppl.): 7-15.

24. Carbon C, Léophonte P. Recommendations posologiques concernant l'amoxicilline et l'amoxicilline-acide clavulanique dans les pneumonies communautaires de l'adulte á l'hôpital. Méd Mal Infect 1997; 27 (Suppl.): 73-78.

25. Lynch JP, Sitring RG. Noninfectious mimics of community-acquired pneumonia. Semin Respir Infect 1993; 8: 14-45.

26. Jokinen C, Heiskanen L, Juvonen H, et al. Incidence of community-acquired pneumonia in the population of four municipalities in Eastern Finland. Am J Epidemiol 1993; 137: 977-988.

27. Fine MJ, Smith DN, Singer DE. Hospitalisation decision in patients with community-acquired pneumonia: a prospective cohort study. Am J Med 1990; 89: 713-721.

28. Fine MJ, Singer DE, Hanusa BH, Lave JR, Kapoor WN.
Validation of a pneumonia prognostic index using the medisgroups comparative hospital database. Am J Med 1993; 94: 153-158.

29. Fine MJ, Hough LJ, Medsger AR, et al. The hospital admission decision for patients with community-acquired pneumonia. Arch Intern Med 1997; 157: 36-44.

30. Coley CM, Li YH, Medsger AR, et al. Preferences for home $v s$ hospital care among low-risk patients with community-acquired pneumonia. Arch Intern Med 1996; 156 : 1565-1571.

31. Fine MJ, Smith MA, Carson CA, et al. Prognosis and outcomes of patients with community-acquired pneumonia. JAMA 1996; 275: 134-141.

32. Branchati FL, Chow JW, Wagener MM, Vacarello SJ, Yu VL. Is pneumonia really the old man's friend? Two-year prognosis after community-acquired pneumonia. Lancet 1993; 342: 30-33.

33. Melbye H, Straume B, Aasebo U, Dale K. Diagnosis of pneumonia in general practice. Relative importance of typical symptoms and abnormal chest signs evaluated against a radiographic reference. Scand J Prim Health Care 1992; 10: 226-233.

34. Woodhead M. Pneumonia in the elderly. J Antimicrob Chemother 1994; 34 (Suppl. A): 85-92. 